\title{
Physical Activity, Diet Compliance with Diabetic Ulcer Incidence in Hospital Makassar City
} Aktivitas Fisik, Kepatuhan Diet terhadap Kejadian Ulkus Diabetic di RSUD Kota Makassar

\author{
Nur Yazlim, Nur Juliana, Elna Sari, Rasniah Sarumi \\ Politeknik Karya Persada Muna
}

\begin{abstract}
Baground: Diabetic foot ulcers are a chronic complication of diabetes in the form of open wounds on the skin surface The prevalence of diabetic foot ulcers in Indonesia is around $13 \%$ of patients treated in hospitals and $26 \%$ of outpatients. The aimed was to determine relationship between physical activity, dietary compliance with the incidence of diabetic ulcers in Hospital Makassar City.

Methods: This type of research used an analytic observational method with a cross sectional study design. Research were taken by accidental sampling and obtained 78 respondents. Data collection is done by filling out questionnaires. The data were analyzed by chi square fisher's exact test.

Results: The results showed that the age of the with the highest incidence of diabetic ulcers was between 45-60 years was $(57,7 \%)$ and the lowest was $>60$ years $(42,3 \%)$, Women were susceptible to the incidence of diabetic ulcers (62,8\%), the highest level of education was high school, namely 50\% and the lowest was elementary school ( $1,3 \%)$ and employment is dominated by private employees $(26,9 \%)$ and the lowest is civil servants $(11,5 \%)$. From 46 respondents with less physical activity (71,8\%) rexperienced the incidence of diabetic ulcers, while from 32 respondents in the moderate category (28,2\%) experienced diabetic ulcers, $p$ value $=0,019$. From 42 respondents in the dietary compliance category, there were (71,8\%) experiencing the incidence of diabetic ulcers, from 11 respondents in the dietadhering category there were (28,2\%) experiencing the incidence of diabetic ulcers, obtained a $p$ value of 0,001.

Conclusion: There are a significant relationship between physical activity, dietary compliance with the incidence of diabetic ulcers in Hospital Makassar City.
\end{abstract}

Keywords: Diabetic ulcer, physical activity, diet compliance

\section{Abstrak}

Pendahuluan: Luka kaki diabetik adalah komplikasi kronik diabetes berupa luka terbuka pada permukaan kulit. Prevalensi terjadinya luka kaki diabetes di Indonesia sekitar 13\% penderta dirawat di Rumah Sakit dan 26\% penderita rawat jalan. Tujuan penelitian untuk mengetahui hubungan aktivitas fisik, kepatuhan diet terhadap kejadian ulkus diabetik di RSUD Kota Makassar.

Metode: Jenis penelitian menggunakan metode observasional analitik dengan rancangan cross sectional study. Responden penelitian diambil dengan accidental sampling dan didapat 78 responden. Pengambilan data dilakukan dengan pengisian kuisioner. Data tersebut dianalisis dengan chi square fisher's exact test.

Hasil: Hasil penelitian menunjukkan bahwa usia responden dengan kejadian ulkus diabetik tertinggi antara 45-60 tahun $(57,7 \%)$ dan terendah $>60$ tahun $(42,3 \%)$, berdasarkan jenies kelamin wanita rentan terhadap kejadian ulkus diabetik (62,8\%), tingkat pendidikan terbanyak SMA yaitu $50 \%$ dan terendah SD $(1,3 \%)$, pekerjaan didominasi oleh pegawai swasta $(26,9 \%)$ dan terendah PNS (11,5\%). Dari 46 responden dengan aktivitas fisik kurang terdapat $(71,8 \%)$ responden mengalami kejadian ulkus diabetik sedangkan dari 32 responden dengan kategori cukup (28,2\%) mengalami kejadian ulkus diabetik nilai $\mathrm{p}$ value $=0,019$. Dari 42 responden dengan kategori kepatuhan diet, terdapat $(71,8 \%)$ mengalami kejadian ulkus diabetik sedangkan dari 11 responden dengan kategori patuh diet terdapat $(28,2 \%)$ mengalami mengalami kejadian ulkus diabetik, diperoleh nilai p 0,001

Kesimpulan: Ada hubungan signifikan antara aktivitas fisik, kepatuhan diet dengan kejadian ulkus diabeti RSUD Kota Makassar.

Kata kunci: Ulkus diabetik, aktivitas fisik, kepatuhan diet

Alamat Korespondensi:

Nur Yazlim

Email : nur.yazlim14@gmail.com

Administrasi Layanan Kesehatan, Politeknik Karya Persada Muna 
ISSN 2798-2408

Diabetes melitus saat ini menjadi salah satu masalah kesehatan yang perlu mendapat perhatian dunia, meskipun bukan tergolong dalam penyakit menular. Penyakit diabetes melitus menjadi penyebab utama ke tujuh kematian pada tahun 2016. Angka kejadian penderita diabetes melitus pada tahun 2015 di seluruh dunia mencapai 415 juta jiwa, dan diperkirakan pada tahun 2040 jumlah penderita diabetes melitus menjadi 642 juta jiwa. Prevalensi diabetes melitus meningkat lebih cepat di negara-negara berpenghasilan menengah dan rendah (WHO, 2016).

Menurut American Diabetes Association (ADA), Diabetes melitus dapat diklasifikasikan menjadi beberapa tipe yakni diabetes melitus tipe 1 , diabetes melitus tipe 2 , diabetes melitus gestasional dan tipe lainnya. Beberapa tipe yang ada, diabetes melitus tipe 2 merupakan salah satu jenis yang paling banyak di temukan yaitu lebih dari 90-95\% (ADA, 2015). Diabetes melitus Tipe 2 merupakan jenis yang paling sering diderita oleh banyak orang. Diabetes melitus Tipe 2 biasanya timbul pada usia di atas 40 tahun, namun bisa pula timbul pada usia lebih muda atau sekitar 20 tahun. Sekitar $90-95 \%$ penderita diabetes adalah diabetes tipe 2 (H Tandra, 2016).

Luka kaki diabetik merupakan komplikasi kronik diabetes berupa luka terbuka pada permukaan kulit yang dapat disertai adanya kematian jaringan setempat. Penderita luka kaki diabetik kurang lebih $12-15 \%$ dari seluruh penderita penderita diabetes dan biasanya terletak pada ekstremitas bawah. Prevalensi terjadinya luka kaki diabetes di Indonesia sekitar 13\% penderta dirawat di Rumah Sakit dan 26\% penderita rawat jalan (Amelia R, 2018). Ada tiga faktor yang berperan dalam pembentukan ulkus kaki diabetik, yaitu neuropati, penyakit arteri perifer dan sepsis. Hal Ini disebabkan karena berkurangnya suplai darah dan nutrisi ke jaringan dan serabut saraf, sehingga menimbulkan iskemia jaringan dan mati rasa karena atropi serabut saraf (Azhari L N, 2016)

Penelitian didapatkan 16 orang mempunyai aktivitas fisik yang baik, dengan kadar glukosa darah normal 15 orang, dan 27 orang mempunyai jenis makanan yang baik dengan kadar glukosa normal 26 orang. Nilai aktivitas fisik $p$ value $=(0,315)>(0,050)$ hubungan aktivitas fisik dan kadar glukosa darah dinyatakan tidak ada (Pamungkasari, 2020). Penelitian menunjukkan bahwa korelasi antara kepatuhan diet pasien diabetes melitus dengan proses penyembuhan luka, diperoleh nilai gamma $=1,000$ dengan signifikansi $p=0,005$ artinya ada hubungan kepatuhan diet pasien diabetes melitus berhubungan dengan penyembuhan luka (Ariani, 2017).

Berdasarkan data yang ditemukan di RSUD Kota Makassar tahun 2016 penyakit diabetes melitus jumlah kasusnya sebesar 3514 penderita. Berdasarkan hal tersebut maka penulis tertarik untuk meneliti Aktivitas Fisik, Kepatuhan Diet terhadap Kejadian Ulkus Diabetik di RSUD Kota Makassar.

\section{METODE PENELITIAN}

Jenis penelitian yang digunakan dalam penelitian ini adalah penelitian kuantitatif, menggunakan metode observasional analitik dengan rancangan cross sectional study. Teknik pengambilan sampel ini adalah accidental sampling yaitu pengambilan sampel yang dilakukan secara kebetulan, yaitu siapa saja yang secara kebetulan bertemu dengan peneliti dapat digunakan sebagai sampel (Sugiyono, 2015). Populasi pasien di RSUD Kota Makassar, sampel pada penelitian ini sebanyak 78 responden. Penelitian ini dilaksanakan pada tahun 2017. Pengambilan data menggunakan kuisioner. Variabel bebas dalam penelitian ini adalah aktivitas fisik, kepatuhan diet sedangkan variabel terikat adalah kejadian ulkus diabetik, untuk mengetahui hubungan antara variabel bebas dengan terikat dengan menggunakan uji chi square fisher's exact test.

\section{HASIL PENELITIAN}


Tabel 1. Distribusi karateristik responden di RSUD Kota Makassar

\begin{tabular}{lcc}
\hline Karakteristik Responden & $\mathbf{n}$ & $\mathbf{\%}$ \\
\hline Umur & 45 & 57,7 \\
$45-60$ Tahun & 33 & 42,3 \\
$>60$ tahun & 78 & 100,0 \\
\hline Jumlah & & \\
\hline Jenis Kelamin & 29 & 37,2 \\
$\quad$ laki-laki & 49 & 62,8 \\
perempuan & 78 & 100,0 \\
\hline Jumlah & & \\
\hline Tingkat Pendidikan & 1 & 1,3 \\
SD & 3 & 3,8 \\
SMP & 39 & 50,0 \\
SMA & 35 & 44,9 \\
Perguruan Tinggi & 78 & 100,0 \\
\hline Jumlah & & \\
\hline Pekerjaan & 9 & 11,5 \\
PNS & 14 & 17.9 \\
Wiraswasta & 21 & 26,9 \\
pegawai swasta & 14 & 17,9 \\
pensiunan & 20 & 25,6 \\
IRT & $\mathbf{7 8}$ & $\mathbf{1 0 0 , 0}$ \\
\hline Jumlah &
\end{tabular}

Sumber: Data Primer 2017

Berdasarkan karakteristik responden sesuai dengan umur dari 78 responden dapat diketahui bahwa responden tertinggi adalah umur $45-60$ tahun sebanyak 45 responden $(57,7 \%)$ dan terendah umur di atas 60 tahun sebanyak 33 responden (43,3\%). Distribusi respoden berdasarkan jenis kelamin, dari 78 responden dapat diketahui bahwa pasien tertinggi perempuan sebanyak 49 responden $(62,8 \%)$ dan pasien terendah dengan jenis kelamin laki-laki sebanyak 29 responden (37,2\%). Distribusi pendidikan dari 78 responden dapat diketahui yang tertinggi dengan tingkat pendidikan SMA sebanyak 39 responden (50,0\%) dan terendah dengan tingkat pendidikan SD sebnayak 1 responden (1,3\%). Berdasarkan pekerjaan dari 78 Responden dapat diketahui bahwa responden tertinggi dengan pekerjaan pegawai swasta sebanyak 21 responden $(26,9 \%)$ dan terendah dengan pekerjaan sebagai Ibu Rumah Tangga (IRT) sebanyak 20 responden $(25,6 \%)$ (tabel 1$)$.

Tabel 2. Distribusi responden berdasarkan aktivitas fisik dan kepatuhan diet di RSUD Kota Makassar

\begin{tabular}{ccc}
\hline Variabel & $\mathbf{N}$ & $\%$ \\
\hline Aktivitas fisik & & \\
Kurang & 46 & 59,0 \\
Cukup & 32 & 41,0 \\
\hline Jumlah & $\mathbf{7 8}$ & $\mathbf{1 0 0 , 0}$ \\
\hline Kepatuhan diet & & 71,8 \\
Tidak patuh & 56 & 28,2 \\
Patuh & 22 & $\mathbf{1 0 0 , 0}$ \\
\hline Jumlah & $\mathbf{7 8}$ &
\end{tabular}

Sumber: Data Primer 2017

Distribusi responden berdasarkan aktivitas fisik di RSUD Kota Makassar dari total responden 78 (100\%), kurang aktivitas fisik sebanyak 46 responden $(59,0 \%)$ dan jumlah responden yang aktivitas cukup 
sebanyak 32 responden (42,3\%). Berdasarkan kepatuhan diet di RSUD Kota Makassar dari total responden $78(100 \%)$ jumlah responden terbanyak adalah tidak patuh sebanyak 56 responden $(71,8 \%)$ dan responden yang patuh sebanyak 22 responden $(28,2 \%)$ (tabel 2 ).

Tabel 3. Hubungan aktivitas fisik dengan kejadian ulkus diabetik di RSUD Kota Makassar

\begin{tabular}{|c|c|c|c|c|c|c|c|}
\hline \multirow{3}{*}{ Aktivitas fisik } & \multicolumn{4}{|c|}{ Kejadian Ulkus Diabetik } & \multicolumn{2}{|c|}{ Total } & \multirow{3}{*}{ p-value } \\
\hline & \multicolumn{2}{|c|}{ Ya } & \multicolumn{2}{|c|}{ Tidak } & \multirow{2}{*}{ n } & \multirow{2}{*}{$\%$} & \\
\hline & $n$ & $\%$ & $n$ & $\%$ & & & \\
\hline Kurang & 28 & 71,8 & 18 & 46,2 & 46 & 100 & \multirow{3}{*}{0,019} \\
\hline Cukup & 11 & 28,2 & 21 & 53,8 & 32 & 100 & \\
\hline Jumlah & 39 & 100 & 39 & 100,0 & 78 & 100 & \\
\hline
\end{tabular}

Sumber: Data Primer, 2017

Berdasarkan penelitian bahwa dari 46 responden dengan kategori aktivitas fisik kurang, terdapat 28 $(71,8 \%)$ responden mengalami kejadian ulkus diabetik. Sedangkan dari 32 responden dengan kategori aktivitas fisik cukup, terdapat $11(28,2 \%)$ responden mengalami kejadian ulkus diabetik. Dari hasil statistik diperoleh nilai $p$ value $=0,019(p<0,05)$ artinya ada hubungan aktivitas dengan kejadian ulkus diabetik. Hal ini menunjukkan bahwa sebagian besar yang mengalami ulkus memiliki aktivitas fisik yang kurang (tabel 3 ).

Tabel 4. Hubungan kepatuhan diet dengan kejadian ulkus diabetik di RSUD Kota Makassar

\begin{tabular}{|c|c|c|c|c|c|c|c|}
\hline \multirow{3}{*}{ Kepatuhan Diet } & \multicolumn{4}{|c|}{ Kejadian Ulkus Diabetik } & \multicolumn{2}{|c|}{ Total } & \multirow{3}{*}{$\mathrm{p}$-value } \\
\hline & \multicolumn{2}{|c|}{$\mathrm{Ya}$} & \multicolumn{2}{|c|}{ Tidak } & \multirow{2}{*}{$\mathbf{n}$} & \multirow{2}{*}{$\%$} & \\
\hline & $n$ & $\%$ & $n$ & $\%$ & & & \\
\hline Tidak patuh & 28 & 71,8 & 14 & 35,9 & 42 & 100 & \\
\hline Patuh & 11 & 28,2 & 25 & 64,1 & 36 & 100 & 0,001 \\
\hline Jumlah & 39 & 100 & 39 & 100,0 & 78 & 100 & \\
\hline
\end{tabular}

Sumber: Data Primer, 2017

Berdasarkan penelitian bahwa dari 42 responden dengan kategori kepatuhan diet, terdapat 28 $(71,8 \%)$ responden mengalami kejadian ulkus diabetik. Sedangkan dari 11 responden dengan kategori patuh diet terdapat 11 responden $(28,2 \%)$ mengalami mengalami kejadian ulkus diabetik. Dari hasil statistik diperoleh nilai $p=0,001(p<0,05)$ artinya ada hubungan kepatuhan diet dengan kejadian ulkus diabetik ( $p$ value $=0,001)$ (tabel 4$)$.

\section{PEMBAHASAN}

Ketidakpatuhan dalam mengikuti program terapi diet dan aktivitas fisik menimbulkan komplikasi diantaranya ulkus diabetik. Ulkus diabetik umumnya sulit disembuhkan dan sangat rentan oleh berbagai infeksi, jika hal tersebut terjadi maka kemungkinan pasien akan kehilangan kakinya.

Hasil penelitian menunjukkan bahwa karakteristik responden berdasarkan usia responden dengan kejadian ulkus diabetik antara 45-60 tahun adalah 57,7\%, berdasarkan jenis kelamin didominasi oleh perempuan (62,8\%). Tingkat pendidikan yang paling banyak SMA yaitu 50\% dan pekerjaan didominasi oleh pegawai swasta $(26,9 \%)$.

Hasil penelitian yang dilakukan oleh (Pardede TE, 2017) menunjukkan bahwa sebagian besar responden dengan diabetes melitus pada rentang usia 45-65 tahun sebesar 70,6\%. Perempuan memiliki peluang peningkatan indeks massa tubuh lebih besar atau memiliki resiko terjadi obesitas lebih tinggi daripada laki-laki serta akibat dari proses hormonal, sindroma siklus bulanan, pasca menopause yang mengakibatkan distribusi lemak tubuh mudah terakumulasi sehingga terjadi resistensi insulin (Harreiter \& 
ISSN 2798-2408

Kautzky-Willer, 2018). Kurangnya pengetahuan mengenai kesehatan pada level pendidikan rendah dapat menjadi penghambat yang akan mengurangi keterlibatan individu dalam program pencegahan maupun pengelolaan penyakit sehingga lebih rentan menderita berbagai penyakit seperti diabetes melitus (Doubova dkk, 2019). Distribusi karakteristik responden berdasarkan pekerjaan menunjukkan sebagian besar ibu rumah tangga dan jenis pekerjaan dihubungkan dengan aktivitas fisik (Puspita, F. A., \& Rakhma, 2018).

Berdasarkan hasil penelitian diperoleh nilai $p$ value $0,019(p<0,05)$. Hal ini menunjukkan bahwa aktivitas fisik mempunyai hubungan dengan kejadian ulkus diabetik. Aktivitas fisik yang kurang mempunyai risiko mengalami ulkus dibetik. Aktivitas fisik dapat meningkatkan penggunaan insulin oleh tubuh sehingga pada orang yang jarang berolahraga, zat makanan yang masuk ke dalam tubuh tidak dibakar tetapi ditimbun sebagai lemak, gula. Selain itu, pasien nekat tidak memakai alas kaki sehingga menimbulkan masalah pada kaki dapat memicu ulkus kaki diabetik. Sedangkan yang memiliki aktivitas kurang dan tidak menderita ulkus kaki diabetik hal ini disebabkan karena pasien selalu menghindari makanan yang dapat memicu peningkatan kadar gula darah, walaupun pasien kurang aktivitas fisik atau olahraga dapat terhindar dari komplikasi ulkus diabetik.

Perawatan kaki yang tidak tepat merupakan salah satu faktor pendorong terjadinya ulkus kaki. (Yoyoh I dkk, 2016) menyatakan bahwa perawatan kaki kurang baik mempunyai peluang 2,463 kali untuk berisiko ulkus kaki pada penderita diabetes melitus. Hasil penelitian yang dilkukan oleh (Zumrotul, 2017) menunjukkan adanya perbedaan yang signifikan penurunan resiko ulkus kaki diabetik pada kelompok perlakuan dan kelompok kontrol dengan nilai $p=0,015(p<0,05)$.

Latihan jasmani yang dianjurkan adalah latihan secara teratur (3-4 kali seminggu selama kurang lebih 30 menit), kemudian tetap melakukan kegiatan sehari-hari seperti berjalan ke pasar, dan lain sebagainya. Aktivitas fisik secara teratur dapat menurunkan berat badan, mengurangi resistensi insulin yang pada akhrinya mampu mengontrol gula darah (A. Z. Muttaqim, 2020).

Berdasarkan hasil penelitian bahwa pasien ulkus diabetik sebanyak $(71,8 \%)$ tidak patuh diet, sedangkan pasien yang tidak menderita ulkus sebanyak $(35,9 \%)$ tidak patuh diet. Pasien yang menderita ulkus diabetik $(28,2 \%)$ patuh diet, sedangkan pasien yang tidak menderita ulkus $(64,1 \%)$ patuh diet. Hal ini menjukan bahwa sebagian besar pasien tidak patuh diet menderita ulkus diabetik.

Kepatuhan diet responden yang mengikuti Prolanis paling banyak didapatkan kategori patuh 47 responden (94,0\%) dalam menjalankan terapi diet DM dan tidak patuh 3 responden (6\%) dalam menjalankan terapi diet. Aktivitas fisik responden yang mengikuti Prolanis paling banyak didapatkan kategori aktivitas sedang yaitu 36 responden (72,0\%) dan didapatkan kategori aktivitas tinggi yaitu 14 responden (28,0\%) (Herawati $\mathrm{N} \mathrm{dkk,} \mathrm{2020).}$

Dari hasil statistik diperoleh nilai $p$ value $0,001(p<0,005)$, hal tersebut menunjukkan bahwa kepatuhan diet mempunyai hubungan dengan kejadian ulkus diabetik. Tidak patuh diet mempunyai risiko terjadinya komplikasi diabetes melitus yaitu ulkus diabetik. Hal ini disebabkan karena pasien yang tidak patuh diet dapat mengonsumsi segala makan yang mengandung karbohidrat sehingga dapat memicu peningkatan gula darah dan meningkatkan risiko terjadinya komplikasi diabetes melitus. Pasien yang patuh diet tidak memiliki resiko terjadinya komplikasi, hal ini disebabkan karena yang mematuhi diet cenderung memilih makanan yang sehat, makanan yang mengandung banyak serat sehingga dapat terhindar dari risiko komplikasi pada penyakit diabetes melitus.

\section{KESIMPULAN DAN SARAN}


Ada hubungan signifikan antara aktivitas fisik dengan kejadian ulkus diabetik dan ada hubungan signifikan antara kepatuhan diet dengan kejadian ulkus diabetik RSUD Kota Makassar.

Saran dari penelitian ini kepada tenaga kesehatan agar lebih sering memberikan pendidikan kesehatan tentang program terapi diet bagi penderita diabetes melitus sehingga dapat lebih memahami bahwa terapi diet baik untuk proses penyembuhan luka; Kepada masyarakat agar senantiasa penjalani pola hidup sehat dan diet nutrisi yang baik serta rutin melakukan olahraga; Kepada peneliti selanjutnya diharapkan dapat melakukan upaya intervensi perbaikan faktor resiko sebagai upaya menurunkan kejadian ulkus kaki diabetik.

\section{DAFTAR PUSTAKA}

ADA. (2015). Physical Activity/Exercise and Diabetes. American Diabetes Association

A.Z.Muttaqim. (2020). Hubungan Dukungan Keluarga dengan Tingkat Kepatuhan Lanjut Usia dalam Melaksanakan Senam Lansia di Posyandu Kondang Waras Desa Ngargorejo Boyolali. Jurnal Keperawatan UMS, 1(1), 11-18.

Amelia, R. (2018). Hubungan Perilaku Perawatan Kaki dengan Terjadinya Komplikasi Luka Kaki Diabetes pada Pasien Diabetes Melitus Tipe 2 di Puskesmas Tuntungan Kota Medan. Tropical Medicine, 1(1), 124-131.

Ariani. (2017). Hubunngan Kepatuhan Diet Pasien dengan Proses Penyembuhan Luka Gangren di Klinik Bedah RSUD dr. Sayidiman Magetan. (Skripsi). Madiun. Stikes Bhakti Husada Mulia.

Azhari. L.N. (2016). Manjemen Stres Pasien Dengan Ulkus Kaki Diabetikum dl RSUD Kota Semarang. (Skripsi). Semarang: Fakultas Kedokteran, Universitas Diponegoro.

Doubova, dkk. (2019). Adequate health literacy is associated with better health outcomes in people with type 2 diabetes in Mexico. Journal Health and Medicine, 24(7), 1-13.

H Tandra. (2016). Diabetes Bisa Sembuh Petunjuk Praktis Mengalahkan dan Menyembuhkan Diabetes. Jakarta: Gramedia Pustaka Utama.

Harreiter dan Kautzky-Willer. (2018). Sex and gender differences in prevention of type 2 diabetes. Frontiers in Endocrinology, 9(220), 1-15.

Herawati N., Martien Sapang., Harna. (2020). Kepatuhan Diet Dan Aktivitas Fisik Pasien Diabetes Melitus Tipe 2 Yang Sudah Mengikuti Prolanis. Nutrire Dianita, 12(1), 16-22.

Pamungkasari. (2020). Hubungan Aktivitas Fisik Dan Jenis Makanan Dengan Kadar Glukosa Darah Penderita Diabetes Melitus Di Puskesmas Dinoyo Kec. Lowokwaru Kota Malang. (Skripsi). Malang: Universitas Tribhuana Tunggadewi (UNITRI).

Pardede TE. (2017). Gambaran Pengendalian Diabetes Melitus Berdasarkan Parameter Indeks Massa Tubuh dan Tekanan Darah di Poli Rawat Jalan Penyakit Dalam RSUD Arifin Achmad Pekanbaru. Jurnal Online Mahasiswa (JOM) Fakultas Kedokteran, 4(1), 1-14.

Puspita, F. A., dan Rakhma, L. R. (2018). Hubungan Lama Kepesertaan Prolanis dengan Tingkat Pengetahuan Gizi dan Kepatuhan Diet Pasien Diabetes Mellitus di Puskesmas Gilingan Surakarta. Jurnal Dunia Gizi, 
1(2), 101-111.

Sugiyono. (2015). Metode Penelitian Kombinasi (Mix Methods). Bandung: Alfabeta.

WHO. (2016). Global Report On Diabetes. France. World Health Organization.

Yoyoh I, Mutaqqin, Nurjana. (2016). Hubungan antara Perawatan kaki dengan resiko ulkus kaki diabetes di ruang rawat inap RSU di Kabupaten Tanggerang. JurnalJKFT, 1(2), 8-15.

Zumrotul, S., Widayati Nur., Hakam Mulia. (2017). Pengaruh Terapiutic Exercise Walking terhadap risiko Ulkus Kaki Diabetik Pada Klien Diabetes Melitus tipe 2 di kelurahan Gebang Kecamatan Patrang Kabupaten Jember. e-Jurnal Pustaka Kesehatan, 5(1), 84-90. 